\title{
PENERAPAN STRATEGI PEMBELAJARAN SESAMA TEMAN DALAM MENINGKATMAN KETERAMPILAN PASSING BAWAH BOLA VOLI PADA SISWA KELAS VII.1 SMP NEGERI 21 PEKANBARU
}

\author{
Aziz \\ SMP Negeri 21 Pekanbaru \\ e-mail: aziz1959@gmail.com
}

\begin{abstract}
Implementation of this Service is downstream of the research results of the background of low passing under the volleyball students of Class IX.1 SMP Negeri 21 Pekanbaru. This study aims to increase passing under volleyball through the implementation of learning strategies among fellow students of Class IX.1 SMP Negeri 21 Pekanbaru, which is held for 1 month. As Subjects in this study are students of Class IX.1 SMP Negeri 21 Pekanbaru. The number of students who made the subject of research as many as 39 students. The form of research is classroom action research. The instrument of this research consists of passing instruments under volleyball and data collection instrument in the form of observation sheet of teacher activity and student activity.

Based on the results of this activity shows that the ability of basic passing motion under the students of Class VII.1 SMP Negeri 21 Pekanbaru can be improved through peer learning strategy. The result of the initial test of student's ability before application of fellow learning strategy is 64,6 or incompetent enough category. When viewed in terms of completeness, only $17.5 \%$ of students declared complete (earned a minimum score of 70). In the first cycle, the average ability of students increased with the category of competence (70.4) with a $52.5 \%$ completeness. In the second cycle, the average ability of students is categorized as competent $(76,9)$ with a mastery of $85 \%$. This shows that the catalytic completeness has been achieved, where the research is said to succeed if the completion of $80 \%$ of students get a score of at least 70
\end{abstract}

Keywords: peer learning strategy, passing down the volleyball

\section{Abstrak}

Pelaksanaan Pengabdian ini merupakan hilirisasi dari hasil Penelitian yang dilatarbelakangi oleh rendahnya passing bawah bola voli siswa Kelas IX.1 SMP Negeri 21 Pekanbaru. Penelitian ini bertujuan untuk meningkatkan passing bawah bola voli melalui penerapan strategi pembelajaran sesama teman siswa Kelas IX.1 SMP Negeri 21 Pekanbaru, yang dilaksanakan selama 1 bulan. Sebagai Subjek dalam Penelitian ini adalah siswa Kelas IX.1 SMP Negeri 21 Pekanbaru. Jumlah siswa yang dijadikan subjek penelitian sebanyak 39 orang siswa. Bentuk penelitian adalah penelitian tindakan kelas. Instrumen penelitian ini terdiri dari instrumen passing bawah bola voli dan instrumen pengumpulan data berupa lembar observasi aktivitas guru dan aktivitas siswa.

Berdasarkan hasil kegiatan ini menunjukkan bahwa kemampuan gerak dasar passing bawah siswa Kelas VII.1 SMP Negeri 21 Pekanbaru dapat ditingkatkan melalui strategi pembelajaran sesama teman. Hasil tes awal kemampuan siswa sebelum diterapkannya strategi pembelajaran sesama adalah 64,6 atau dalam kategori cukup kompeten. Jika dilihat dari segi ketuntasan, hanya $17,5 \%$ siswa yang dinyatakan tuntas (memperoleh nilai minimal 70), Pada siklus pertama kemampuan rata-rata siswa meningkat dengan kategori nilai kompeten $(70,4)$ dengan ketuntasan sebesar 52,5\%. Pada siklus kedua kemampuan rata-rata siswa dikategorikan kompeten (76,9) dengan ketuntasan sebesar 85\%. Hal ini menunjukkan bahwa ketuntasan kasikal telah tercapai, dimana penelitian dikatakan berhasil bila ketuntasan yang dicapai $80 \%$ siswa memperoleh nilai minimal 70

Kata kunci : strategi pembelajaran sesama teman, passing bawah bola voli 


\section{PENDAHULUAN}

Pendidikan jasmani telah diajarkan mulai dari pendidikan dasar, hal ini menggambarkan betapa pentingnya pendidikan jasmani untuk membentuk generasi yang sehat. Pendidikan jasmani disekolah dasar mengajarkan berbagai ketrampilan dasar bermacam-macam permainan, cara hidup sehat, dan lain-lain. Masa anak-anak merupakan masa dimana paling senang bermain, melakukan aktifitas yang dapat menyenangkan mereka. Tanpa disadari kadang-kadang permainan mereka telah melatih aspek psikomotor mereka. Salah satu olahraga yang melatih gerak psikomotor adalah olahraga bola voli. Hal ini dikarenakan setiap gerakan bola voli membutuhkan kekuatan fisik yang baik.

Permainan bola voli dahulunya merupakan permainan rekreasi yang dimainkan semata-mata dilakukan untuk hiburan saja. Seiring dengan semakin berkembangnya bola voli, kini permainan bola voli telah berkembang menjadi olahraga prestasi yang sangat populer. Untuk memainkan permainan bola voli dibutuhkan gerak dasar yang baik agar permainan tersebut menarik. Gerak dasar bola voli terdiri dari servis, passing, smash dan block. Dari gerak dasar tersebut yang memegang peranan penting yaitu teknik passing. Fungsi teknik passing untuk mengumpan, menahan servis, menahan smesh, dan memantulkan bola (tim abdi guru 2006:60).

Dari hasil pengamatan dan pengalaman penulis yang juga guru penjas di Kelas VII.1 SMP Negeri 21 Pekanbaru ditemui beberapa gejala sebagai berikut : 1) Sebagian besar siswa enggan bermain bola voli karena susah dimainkan, 2) Dalam bermain bola voli, masih banyak siswa yang belum menggunakan gerak dasar dengan benar, 3) Sebagian besar siswa belum mampu melakukan passing bawah dalam permainan bola voli sehingga bola hasil passing siswa sulit diarahkan kepada temannya

Dari beberapa gejala diatas dapat disimpulkan bahwa gerak dasar bola voli belum dikuasai dengan baik oleh siswa. Hal ini mungkin dikarenakan cara mengajar guru yang kurang dimengerti oleh siswa. Dalam praktik pendidikan jasmani gaya mengajar yang dilakukan oleh guru cenderung konvensional. Model metode-metode praktik dipusatkan pada guru (Teacher Centered) dimana para siswa melakukan latihan fisik berdasarkan perintah yang ditentukan oleh guru. Latihan-latihan tersebut hampir tidak pernah dilakukan oleh anak sesuai dengan inisiatif sendiri (Student Centered). Kondisi seperti ini mengakibatkan tidak optimalnya fungsi pengajaran pendidikan jasmani sebagai medium pendidikan dalam rangka pengembangan pribadi anak seutuhnya.

Menyikapi hal tersebut, penggunaan metode pengajaran yang berpusat pada siswa. Siswa yang diaggap telah memiliki gerak dasar passing yang baik dapat mengajarkan kepada siswa yang belum menguasai gerak dasar passing. Strategi pembelajaran sesama teman (peer teaching) merupakan strategi yang diaggap tepat untuk mengatasi masalah ini dan meningkatkan kemampuan passing bawah pada siswa. Oleh karena itu peneliti tertarik ingin melakukan penelitian dengan judul "Penerapan Strategi Pembelajaran Sesama Teman Dalam Meningkatman Keterampilan Passing Bawah Bola Voli Pada Siswa Kelas VII.1 SMP Negeri 21 Pekanbaru".

\subsection{Lokasi penelitian}

\section{METODOLOGI}

Pelaksanaan pengabdian ini dilakukan dilakukan di SMP Negeri 21 Pekanbaru.

\subsection{Subjek dan ObjekPenelitian}

Subjek dalam pelaksanaan ini adalah siswa Kelas VII.1 SMP Negeri 21 Pekanbaru yang berjumlah 40 siswa. Penelitian dilakukan selama semester ganjil Tahun 2016

Bentuk penelitian ini adalah Penelitian Tindakan Kelas (PTK). Wiriaatmadja (2005:12) menyatakan penelitian tindakan kelas adalah kajian sistematik dari upaya perbaikan pelaksanaan praktek pendidikan oleh sekolompok guru dengan melakukan tindakan-tindakan dalam pembelajaran, berdasarkan refleksi mereka mengenai hasil tindakan-tindakan tersebut.

Sedangkan menurut Arikunto (2006:16) menyatakan bahwa penelitian tindakan kelas (PTK) adalah penelitian yang dilakukan dikelas dengan tujuan memperbaiki atau meningkatkan mutu praktik pembelajaran. Penelitian ini dilakukan dalam dua siklus, tahapan siklus penelitian tindakan kelas (PTK) menurut Arikunto (2006:16) adalah sebagai berikut : 
a. Merencanakan : Rencana tindakan kelas "Apa" yang akan dilakukan untuk memperbaiki, meningkatkan atau perubahan tingkah laku dan sikap sebagai solusi.

b. Tindakan : apa yang harus dilakukan oleh guru atau peneliti sebagai upaya perbaikan, peningkatan atau perubahan yang diinginkan.

c. Mengamati : Mengamati aktivitas atau dampak dari tindakan yang dilaksanakan atau dikenakan terhadap siswa. Tujuannya untuk mengetahui kualitas pelaksanaan tindakan.

d. Refleksi : Peneliti mengkaji, melihat dan mempertimbangkan atas aktivitas belajar dalam mengikuti pelajaran berbagai kriteria. Tujuannya adalah mengetahui kekuatan dan kelemahan dari tindakan yang dilakukan untuk dapat diperbaiki pada siklus berikutnya.

\section{Perencanaan Tindakan}

Penelitian ini menggunakan rancangan Penelitian Tindakan Kelas. Peneliti dalam penelitian adalah sebagai pelaksana penelitian, pengumpul data, penganalisis data, dan pelapor hasil penelitian. Selain itu, peneliti juga meminta bantuan kepada teman sejawat untuk menjadi observer. Tugas dari observer dalam penelitian ini adalah mengamati aktivitas peneliti / guru, dan membantu guru dalam mengamati aktivitas siswa. Penelitian terdiri dari 2 siklus, masing-masing siklus melalui tahapan perencanaan, pelaksanaan, observasi, dan refleksi tindakan.

\section{Keberhasilan}

Penelitian menetapkan ketercapaian indikator kemampuan passing bawah adalah 70 untuk masing-masing siswa. Sedangkan indikator klasikal adalah 80\% siswa mendapat nilai 70, baru dianggap berhasil (KTSP, 2007:382). Artinya setiap siswa dikatakan berhasil apabila memperoleh nilai 70.

\section{Teknik Pengumpulan Data}

Untuk mengumpulkan data penelitian, peneliti menggunakan dua alat yaitu berupa tes dan nontes. Teknik tes digunakan untuk menjaring data berkaitan dengan kemampuan siswa dalam melakukan ketrampilan passing bawah. Sedangkan teknik non tes adalah teknik yang digunakan peneliti dalam rangka menilai keberhasilan dan kekurangan proses pembelajaran yang dilakukan, dalam hal ini menggunakan teknik observasi. Menjaring data dengan teknik tes dengan cara meminta siswa mengerjakan tugas yang telah disiapkan. Pemberian tugas ini selalu berkaitan dengan materi pelajaran. Penerapan teknik non tes dalam rangka menjaring data penelitian yaitu, peneliti dan observer melakukan pengamatan serta mencatat hal-hal yang dilakukan oleh peneliti.

\section{Teknik Analisis Data}

1. Kemampuan Passing Bawah

Dalam pendidikan jasmani atau lingkup olahraga, pengukuran dilakukan pada ranah:

1) Pengukuran ranah kognitif

Pengukuran ranah ini mengukur pengetahuan yang dimiliki sehubungan dengan teknik, peraturan, dan strategi-strategi olehraga, konsep sehubungan dengan pengembangan dan cara pencegahan cedera, dan lain-lain.

2) Pengukuran ranah afektif

Pengukuran ranah ini mengukur minat, perhatian, sikap, perasaan, dan nilai dalam hubungannya dengan aktivitas fisik yang bermakna. Selain itu, mengukur sifat agresif, ketagihan berlatih, dan kecemasan dalam menghadapi kompetisi.

3) Pengukuran ranah psikomotor

Pengukuran ranah ini mengukur keterampilan motorik, perkembangan motorik, dan kesegaran jasmani. Pada umumnya tes psikomotor meliputi dua hal: a) produk performa motorik mengukur kecepatan, kekuatan, keajegan servis, dan lain-lain, dan b) proses pelaksanaan performa mengukur pola yang digunakan untuk melakukan servis badminton misalnya. (Ismaryati, 2008:5).

Untuk melakukan penilaian terhadap 3 ranah tersebut diuraikan sebagai berikut: 
1) Pengukuran ranah kognitif

Aspek yang dinilai untuk mengukur kemampuan passing bawah siswa pada ranah kognitif adalah melalui tes secara tertulis.

2) Pengukuran ranah afektif

Aspek yang dinilai untuk mengukur kemampuan passing bawah siswa pada ranah afektif adalah melalui observasi terhadap minat, perhatian, sikap, perasaan, dan nilai dalam hubungannya dengan aktivitas fisik yang bermakna.

3) Pengukuran ranah psikomotor

Aspek yang dinilai untuk mengukur kemampuan passing bawah siswa pada ranah psikomotor adalah :

a. Kedua lutut ditekuk

b. Bandan condong kedepan

c. Tangan lurus kedepan (antara lutut dan bahu)

d. Persentuhan bola pada pergelangan tangan

e. Pandangan mata kedepan

f. Koordinasi gerakan lutut, badan dan bahu. Sukrisno dkk (2007:60)

Adapun format penilaian dapat dilihat pada tabel 1 berikut ini:

Tabel 1

Contoh Rubrik Penilaian

\begin{tabular}{|l|c|c|c|c|}
\hline \multirow{2}{*}{ Aspek yang dinilai } & \multicolumn{5}{|c|}{ Kulitas Gerak } \\
\cline { 2 - 5 } & 1 & 2 & 3 & 4 \\
\hline Kedua lutut ditekuk & & & $\checkmark$ & \\
\hline Bandan condong kedepan & & & & $\checkmark$ \\
\hline $\begin{array}{l}\text { Tangan lurus kedepan (antara lutut dan } \\
\text { bahu) }\end{array}$ & & & $\checkmark$ & \\
\hline $\begin{array}{l}\text { Persentuhan bola pada pergelangan } \\
\text { tangan }\end{array}$ & & $\checkmark$ & & \\
\hline Pandangan mata kedepan & & $\checkmark$ & & \\
\hline $\begin{array}{l}\text { Koordinasi gerakan lutut, badan dan } \\
\text { bahu }\end{array}$ & & & $\checkmark$ & \\
\hline jumlah & & \multicolumn{3}{|c|}{17} \\
\hline Jumlah Skor Maksimal & \multicolumn{5}{|c|}{24} \\
\hline
\end{tabular}

Skala nilai : 4 = baik, $3=$ cukup baik, $2=$ kurang baik, $1=$ tidak baik

Maka penilaiannya adalah:

Nilai $=\frac{\text { jumla skor yang diperoleh }}{\text { skormaksimal }} \times 100$

maka:

Nilai $=\frac{17}{24} x 100=70$

70 terletak antara rentang 70-89 dengan kategori kompeten (samsudin, 2009:293) 
Tabel 2

Interval Kategori Kemampuan

Passing Bawah siswa

\begin{tabular}{|c|c|c|}
\hline NO & Interval & Kategori \\
\hline 1 & $90 \mathrm{sd} 100$ & Sangat Kompeten \\
\hline 2 & $70 \mathrm{sd} 89$ & Kompeten \\
\hline 3 & $50 \mathrm{sd} 69$ & Cukup Kompeten \\
\hline 4 & $30 \mathrm{sd} 49$ & Kurang Kompeten \\
\hline 5 & $10 \mathrm{sd} 29$ & Tidak Kompeten \\
\hline
\end{tabular}

2. Ketuntasan belajar

Sumber: KTSP (2007:367)

Ketuntasan individu tercapai apabila siswa mencapai nilai 70 (KTSP, 2007:382). Ketuntasan klasikal tercapai apabila $80 \%$ dari seluruh siswa mampu menguasi kemampuan passing bawah dengan baik atau mendapatkan nilai 70 keatas. Rumus yang dipergunakan untuk menentukan ketuntasan klasikal sebagai berikut:

$$
\begin{array}{ll}
P=\frac{F}{N} & x 100 \% \text { (Anas Sudijono, 2004:23) } \\
\mathrm{P} & =\text { Angka persentase ketuntasan klasikal } \\
\mathrm{F} & =\text { Frekuensi siswa yang tuntas } \\
\mathrm{N} & =\text { Jumlah siswa }
\end{array}
$$

3. Aktivitas guru

Yang dinilai dari aktivitas guru adalah cara mengajar guru dengan menerapkan strategi pembelajaran sesama teman. Rumus yang dinilai dari aktifitas guru adalah :

$$
\text { Nilai }=\frac{\text { Skor Yang didapat }}{\text { Skor Maksimum }} \times 100
$$

Tabel 3

Kategori Aktivitas Guru

\begin{tabular}{|c|c|c|}
\hline NO & Interval & Kategori \\
\hline 1 & $90 \mathrm{sd} 100$ & Sangat Baik \\
\hline 2 & $70 \mathrm{sd} 89$ & Baik \\
\hline 3 & $50 \mathrm{sd} 69$ & Sedang \\
\hline 4 & $30 \mathrm{sd} 49$ & Kurang \\
\hline 5 & $10 \mathrm{sd} 29$ & Sangat Kurang \\
\hline
\end{tabular}

(KTSP, 2007:367)

4. Aktivitas siswa

Pada lembaran observasi, setiap siswa melakukan aktivitas diberi tanda ceklis $(\sqrt{ })$, sedangkan siswa yang tidak melakukan aktivitas dikosongkan. interval dan kategori aktivitas guru dan siswa adalah sebagai berikut:

$$
\text { Nilai }=\frac{\text { Skor Yang didapat }}{\text { Skor Maksimum }} \times 100
$$

Tabel 4

Kategori Aktivitas Siswa

\begin{tabular}{|c|c|c|}
\hline NO & Interval & Kategori \\
\hline 1 & $90 \mathrm{sd} 100$ & Sangat Baik \\
\hline 2 & $70 \mathrm{sd} 89$ & Baik \\
\hline 3 & $50 \mathrm{sd} 69$ & Sedang \\
\hline 4 & $30 \mathrm{sd} 49$ & Kurang \\
\hline 5 & $10 \mathrm{sd} 29$ & Sangat Kurang \\
\hline
\end{tabular}

(KTSP, 2007:367) 


\section{HASIL DAN PEMBAHASAN}

Analisis data pada pelaksanaan kegiatan ini diperoleh dari analisis daya serap, ketuntasan hasil belajar, aktivitas siswa, dan aktivitas guru melalui strategi pembelajaran sesama teman. Adapun uraiannya adalah sebagai berikut:

1. Daya Serap atau Kemampuan Gerak dasar

Daya serap atau kemampuan siswa dari tes awal, siklus I, dan siklus II dapat dianalisis sebagai berikut:

1. Nilai sangat kompeten $(90-100)$, pada tes awal dan siklus I kategori nilai ini tidak diperoleh seluruh siswa. Sedangkan siklus kedua ada $5 \%$ siswa.

2. Nilai kompeten $(70$ - 89 , pada tes awal terdapat $17,5 \%$ siswa, siklus pertama ada $52,5 \%$ siswa, sedangkan siklus kedua meningkat dengan $80 \%$ siswa.

3. Nilai cukup kompeten (50-69), pada tes awal terdapat $82,5 \%$ siswa, siklus pertama ada $47,5 \%$ siswa, sedangkan siklus kedua meningkat dengan $15 \%$ siswa.

4. Nilai kurang kompeten $(30-49)$, pada kategori nilai ini tidak diperoleh seluruh siswa, dan

5. Nilai tidak kompeten $(10-29)$, pada nilai ini tidak diperoleh seluruh siswa.

Untuk lebih jelasnya dapat dilihat pada tabel 17 berikut ini.

Tabel 5

Kemampuan Passing bawah Siswa Pada Tes Awal, Siklus I dan Siklus II

\begin{tabular}{|c|c|c|c|c|c|}
\hline \multirow[t]{2}{*}{ No } & \multirow[t]{2}{*}{ Interval } & \multirow[t]{2}{*}{ Kategori } & \multicolumn{3}{|c|}{ Daya Serap (\%) } \\
\hline & & & Tes Awal & Siklus I & Siklus II \\
\hline 1 & $90 \mathrm{sd} 100$ & Sangat Kompeten & 0 & 0 & $\overline{5,0}$ \\
\hline 2 & $70 \mathrm{sd} 89$ & Kompeten & 17,5 & 52,5 & 80,0 \\
\hline 3 & 50 sd 69 & Cukup Kompeten & 82,5 & 47,5 & 15,0 \\
\hline 4 & $30 \mathrm{sd} 49$ & Kurang Kompeten & 0 & 0 & 0 \\
\hline 5 & $10 \mathrm{sd} 29$ & Tidak Kompeten & 0 & 0 & 0 \\
\hline \multicolumn{3}{|r|}{ Jumlah (\%) } & 100 & 100 & 100 \\
\hline \multicolumn{3}{|r|}{ Jumlah Siswa } & \multicolumn{3}{|c|}{40} \\
\hline \multicolumn{3}{|c|}{ Daya Serap Tiap Siklus } & 64,6 & 70,4 & 76,9 \\
\hline & & aya Serap Rata-rata & \multicolumn{3}{|c|}{70,6} \\
\hline
\end{tabular}

Daya serap siswa dari tes awal, siklus pertama, dan siklus kedua juga dapat dilihat dalam bentuk gambar di bawah ini.

\section{Ketuntasan Hasil Belajar Siswa}

Ketuntasan kemampuan passing bawah siswa Kelas VII.1 SMP Negeri 21 Pekanbaru selama pembelajaran melalui strategi pembelajaran sesama teman adalah $90,6 \%$, hal ini dapat dilihat pada tabel di bawah ini.

Tabel 6.

Ketuntasan Hasil Belajar Siswa dari Tes Awal, Siklus I dan Siklus II

\begin{tabular}{|c|c|c|c|c|}
\hline Pembelajaran & Kriteria & Jumlah & $\%$ & Kategori \\
\hline \multirow{2}{*}{ Tes Awal } & Tuntas & 7 & $17,5 \%$ & \multirow{2}{*}{ TT } \\
\cline { 2 - 4 } & Tidak Tuntas & 33 & $82,5 \%$ & \\
\hline \multirow{2}{*}{ Siklus I } & Tuntas & 21 & $52,5 \%$ & \multirow{2}{*}{ TT } \\
\cline { 2 - 4 } & Tidak Tuntas & 19 & $47,5 \%$ & \\
\hline \multirow{2}{*}{ Siklus II } & Tuntas & 34 & $85,0 \%$ & \multirow{2}{*}{$\mathrm{T}$} \\
\cline { 2 - 4 } & Tidak Tuntas & 6 & $15,0 \%$ & \\
\hline
\end{tabular}


Ketuntasan siswa pada tes awal, Siklus I dan Siklus II juga ditampilkan dalam bentuk gambar 1 di bawah ini.

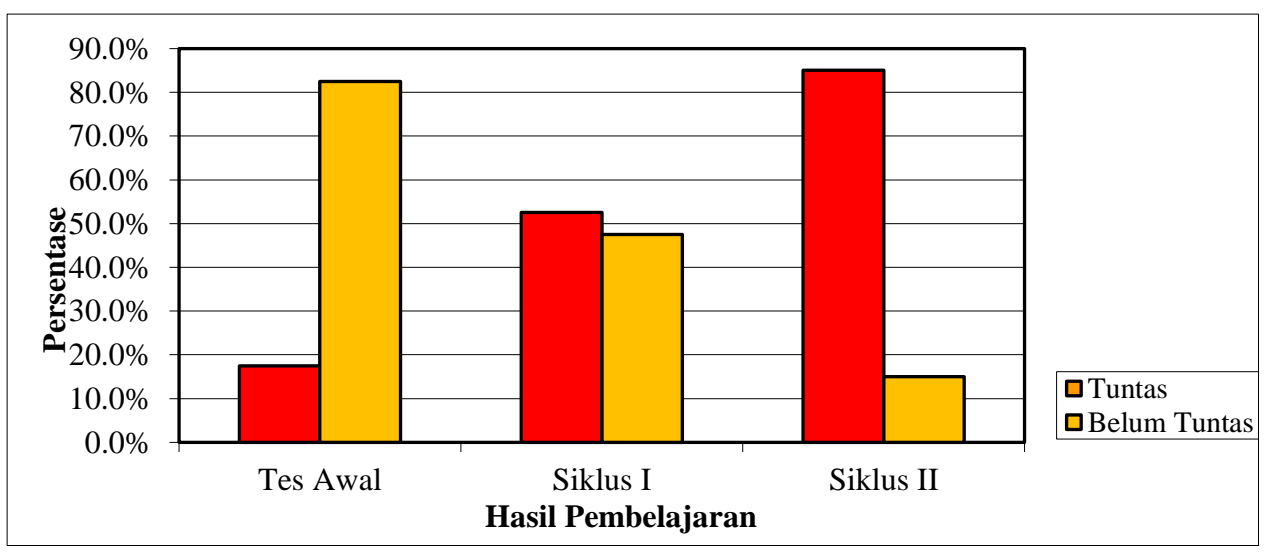

Gambar 1. Grafik Ketuntasan Hasil Belajar Siswa pada Tes Awal, Siklus I dan Siklus II Aktivitas Siswa

Baiknya kemampuan siswa dalam menguasai gerak dasar passing bawah bola voli tidak terlepas dari baiknya aktivitas mereka dalam belajar. Hal tersebut dapat tergambar pada uraian sebagai berikut

1. Membentuk kelompok dengan cepat dan benar. Pada siklus I ada 26 siswa yang melaksanakannya, sedangkan siklus kedua meningkat dengan 29 siswa.

2. Mengikuti insruksi dan bimbingan dari guru dengan baik. Pada aspek ini ada 30 siswa yang melaksanakannya, sedangkan siklus kedua meningkat dengan 32 siswa

3. Siswa mengadakan pembelajaran sesama temannya sesuai dengan formasi yang telah ditentukan guru. Pada siklus I ada 28 siswa yang melaksanakannya, sedangkan siklus kedua meningkat dengan 32 siswa

4. Siswa tetap tertib selama proses pembelajaran berlangsung. Pada siklus I ada 29 siswa yang melaksanakannya, sedangkan siklus kedua meningkat dengan 31 siswa

5. Menjalankan klarifikasi dari guru dengan benar. Pada siklus I ada 28 siswa yang melaksanakannya, sedangkan siklus kedua meningkat dengan 34 siswa

6. Mengikuti evaluasi dengan baik. Pada siklus I ada 28 siswa yang melaksanakannya, sedangkan siklus kedua meningkat dengan 32 siswa.

Untuk lebih jelasnya dapat dilihat pada tabel 19 berikut ini.

Tabel 7.

Aktivitas Siswa Siklus I dan Siklus II

\begin{tabular}{|c|l|c|c|c|c|c|c|}
\hline No & \multicolumn{1}{|c|}{ Aktivitas Siswa } & \multicolumn{2}{c|}{ Siklus I } & \multicolumn{2}{c|}{ Siklus II } & \multicolumn{2}{c|}{ Rata-rata } \\
\cline { 4 - 8 } & \multicolumn{1}{|c|}{$\begin{array}{l}\text { Jlh } \\
\text { Membentuk kelompok dengan cepat dan } \\
\text { benar }\end{array}$} & 27 & $67,5 \%$ & 29 & $72,5 \%$ & 28 & $70,0 \%$ \\
\hline 2 & $\begin{array}{l}\text { Mengikuti insruksi dan bimbingan dari } \\
\text { guru dengan baik }\end{array}$ & 30 & $75,0 \%$ & 32 & $80,0 \%$ & 31 & $77,5 \%$ \\
\hline & $\begin{array}{l}\text { Siswa mengadakan pembelajaran } \\
\text { sesama temannya sesuai dengan formasi } \\
3\end{array}$ & 28 & $70,0 \%$ & 32 & $80,0 \%$ & 30 & $75,0 \%$ \\
\hline 4 & $\begin{array}{l}\text { Siswa tetap ditentukan guru } \\
\text { pembelajaran berlangsung selama proses }\end{array}$ & 29 & $72,5 \%$ & 31 & $77,5 \%$ & 30 & $75,0 \%$ \\
\hline 5 & $\begin{array}{l}\text { Menjalankan klarifikasi dari guru } \\
\text { dengan benar }\end{array}$ & 28 & $70,0 \%$ & 34 & $85,0 \%$ & 31 & $77,5 \%$ \\
\hline 6 & Mengikuti evaluasi dengan baik & 28 & $70,0 \%$ & 32 & $80,0 \%$ & 30 & $75,0 \%$ \\
\hline
\end{tabular}

Sumber: Data Olahan Penelitian, Tahun 2016 


\section{Aktivitas Guru}

Gambaran aktivitas guru melalui strategi pembelajaran sesama teman pada siklus pertama adalah 70 dengan kategori baik, sedangkan siklus kedua adalah 80 (baik). Sehingga diperoleh rata-rata keseluruhan sebesar 75 atau dengan kategori baik. Hal ini menggambarkan bahwa rata-rata pembelajaran yang dibawakan guru adalah baik. Untuk lebih jelasnya dapat dilihat pada tabel di bawah ini.

Tabel 8.

Aktivitas Guru Siklus I dan Siklus II

\begin{tabular}{|c|l|c|c|}
\hline No & Pembelajaran & Rata-rata Skor & Kategori \\
\hline 1 & Siklus I & 70,0 & Baik \\
\hline 2 & Siklus II & 80,0 & Baik \\
\hline \multicolumn{2}{|c|}{ Rata-rata } & 75,0 & Baik \\
\hline
\end{tabular}

Sumber: Data Olahan Penelitian, Tahun 2016

\section{KESIMPULAN}

Berdasarkan hasil penelitian dan pembahasan, bahwa kemampuan gerak dasar passing bawah siswa Kelas VII.1 SMP Negeri 21 Pekanbaru dapat ditingkatkan melalui strategi pembelajaran sesama teman. Pernyataan ini diperkuat oleh hasil yang telah dikemukakan sebelumnya, yakni:

1. Hasil tes awal kemampuan siswa sebelum diterapkannya strategi pembelajaran sesama adalah 64,6 atau dalam kategori cukup kompeten. Jika dilihat dari segi ketuntasan, hanya 17,5\% siswa yang dinyatakan tuntas (memperoleh nilai minimal 70),

2. Pada siklus pertama kemampuan rata-rata siswa meningkat dengan kategori nilai kompeten $(70,4)$ dengan ketuntasan sebesar 52,5\%,

3. Pada siklus kedua kemampuan rata-rata siswa dikategorikan kompeten $(76,9)$ dengan ketuntasan sebesar $85 \%$. Hal ini menunjukkan bahwa ketuntasan kasikal telah tercapai, dimana penelitian dikatakan berhasil bila ketuntasan yang dicapai $80 \%$ siswa memperoleh nilai minimal 70 .

\section{SARAN}

Melihat dan menganalisa hasil dan kesimpulan penelitian, maka peneliti ingin menyampaikan beberapa saran. Saran yang dimaksud adalah sebagai berikut:

1. Kepada guru Pendidikan Jasmani dan Kesehatan dapat meningkatkan kemampuan gerak dasar passing bawah melalui strategi pembelajaran sesama teman.

2. Kepada peneliti selanjutnya agar meneliti lebih dalam tentang strategi pembelajaran sesama teman dan kemampuan gerak dasar passing bawah dan strategi pembelajaran sesama teman, demi kesempurnaan penelitian selanjutnya.

3. Kepada kepala sekolah perlu memamtau dan membina terhadap dampak kegiatan Penelitian Tindakan Kelas (PTK), sebagai bahan penilaian kemajuan yang telah dicapai, sehingga apa yang ditemukan pada PTK dapat diimplementasikan dalam pelaksanaan pembelajaran di sekolah.

4. Kepada pengawas perlu mengadakan kunjungan supervisi terhadap peneliti dalam pelaksanaan PTK sedang berlangsung, agar apa yang ditemukan dapat diimplementasikan pada proses pelaksanaan pembelajaran.

\section{DAFTAR PUSTAKA}

[1] Anas Sudijono. 2004. Pengantar Statistik Pendidikan. Jakarta. Raja Grafindo Persada

[2] Arikunto. 2006. Penelitian Tindakan Kelas. Jakarta: Bumi Aksara

[3] Husdarta. 2009, Manajemen Pendidikan Jasmani. Alfabeta,Bandung.

[4] Ismaryati. 2008. Tes \& Pengukuran Olahraga. Surakarta: UNS Press.

[5] KTSP. 2007. Panduan Lengkap KTSP. Yokyakarta. Pustaka Yudhistira 
[6] Mukholid, Agus. 2007. Pendidikan Jasmani Olahraga dan Kesehatan. Surakarta: Yudistira

[7] Samsudin. 2008. Pembelajaran Pendidikan Jasmani Olahraga dan Kesehatan. Jakarta: Litera Prenada Media Group

[8] Silbermen Mel. 2002. Active Learning. Yogyakarta: Yappendis.

[9] Yenita Roza, Evi Suryawati, Mitri Irianti, Herdini. 2009. Buku Penelitian. Pekanbaru:

[10] Zaini dkk. 2007. Strategi Pembelajaran Aktif. Yogyakarta: CTSD. 